\title{
Genetic Variations of Candida albicans Isolated from Clinical Specimens Using Multi-locus Sequence Typing Analysis
}

\author{
Hee-Jin Kim ${ }^{1, \dagger}$, Sang-Ha Kim ${ }^{2, \dagger}$, Sunghyun $\mathrm{Kim}^{3}$, Young-Bin $\mathrm{Yu}^{4}$, Young-Kwon $\mathrm{Kim}^{4}$ \\ ${ }^{1}$ Department of Laboratory Medicine, Sun General Hospital, Daejeon, Korea \\ ${ }^{2}$ Department of Laboratory Medicine, Konyang University Hospital, Daejeon, Korea \\ ${ }^{3}$ Department of Clinical Laboratory Science, College of Health Sciences, Catholic University of Pusan, Busan, Korea \\ ${ }^{4}$ Department of Biomedical Laboratory Science, College of Medical Sciences, Konyang University, Daejeon, Korea
}

\section{임상 검체에서 분리된 Candida albicans의 MLST를 이용한 유전적 변이 특성}

김희진 ${ }^{1, \dagger}$, 김상하 $^{2, \dagger}$, 김성현 ${ }^{3}$, 유영빈 ${ }^{4}$, 김영권 $^{4}$

${ }^{1}$ 대전선병원 진단검사의학과, ${ }^{2}$ 건양대학교병원 진단검사의학과, ${ }^{3}$ 부산가톨릭대학교 보건과학대학 임상병리학과, ${ }^{4}$ 건양대학교 의과학대학 임상병리학과

\begin{abstract}
In this study, multi-locus sequence typing (MLST) analysis of 40 clinically isolated Candida albicans in tertiary hospitals in Daejeon, Korea, confirmed the nucleotide sequence and phylogenetic relationships of the strains collected from different specimen sources. The general variations found in seven different housekeeping genes of $C$. albicans, collected from urine and sputum, peripheral blood, central line blood, and other specimens, were analyzed. The phylogenetic tree was divided into 18 sub-clusters (1), a central line blood (2), others (5), sputum (1), peripheral blood (6), sputum (1), and urine (1), and the isolates at the same site were confirmed to have genetic similarity. Consequently, genetic similarity and the potential relevance were found in the strains collected from the same specimen sources. MLST analysis of $C$. albicans suggests that persistent data accumulation of phylogenetic gene variations of $C$. albicans may help establish infectious disease studies and epidemiological surveillance systems.
\end{abstract}

Key words: Clinical specimens, Candida albicans, Genetic variation, MLST analysis

This is an Open Access article distributed under the terms of the Creative Commons Attribution Non-Commercial License (http://creativecommons.org/licenses/by-nc/4.0) which permits unrestricted non-commercial use, distribution, and reproduction in any medium, provided the original work is properly cited.

Copyright (@) 2018 The Korean Society for Clinical Laboratory Science. All rights reserved.
${ }^{\dagger}$ The first two authors contributed equally to this work.

Corresponding author: Young-Kwon Kim Department of Biomedical Laboratory Science, College of Medical Sciences, Konyang University, 158 Gwanjeodong-ro, Seo-gu, Daejeon 35365, Korea Tel: 82-42-660-6371

Fax: 82-42-543-6370

E-mail: ykkim3245@konyang.ac.kr

Received: July 9, 2018 Revised: August 4, 2018 Accepted: August 10, 2018
서 론

Candida속은 노약자, 어린이 또는 항암제 치료를 받거나장기 이식을 받은 면역이 약화한 환자에게 국소 또는 기회감염을 일으 킨다[1]. Candida 속의 분리 빈도에 대해 최근 10 년간 보고된 바 에 따르면 이에 대한 감염률이 점점 증가하고 있는 추세이다[2].
Candida 속은 이미 유럽에서 병원감염의 중요한 병원체로 중대하게 다루어지고 있다. 기회감염의 가능성이 큰 중환자에 게서는 사망률이 $40 \%$ 에 달하고 있으며[3], 면역이 저하된 사람 이나 이식된 인공장치 혹은 중심정맥 수액 등 처치를 받는 환자 에서의 발병률과 치사율이 높아 이에 대한 진단과 치료가 매우 중요한 사항이 된다 $[4,5]$. 특히 혈액배양에서의 Candida 속 양 
성은 패혈증으로 이어지므로 이에 대한 감염주의가 절대적으로 필요한 실정이며, 무엇보다 감염되었을 때 빠른 진단과 적절한 치료제 선택이 요구된다[6].

최근에는 항균제의 과다 사용, 환경적 요인 등으로 인한 Candida 속의 내성률이 높아지고 있으며, 이에 따른 유전학적 변이 균주가 증가하여 임상적으로 치료의 실패 및 사망률 증가 로 이어지고 있다[7]. 또한 이러한 유전적 변이 축적이 각종 암 발생의 원인이 될 수 있다는 주장이 제기되면서 원인균을 밝혀 냄과 동시에 해당 균주마다 지니고 있는 유전적 특성을 밝혀내 는 것이 중요하게 다루어지고 있다[8].

현재 임상에서 주로 시행되고 있는 Candida 속에 대한 분류 동정은 배양 집락의 관찰과 Germ tube 확인검사, $10 \% \mathrm{KOH}$ 검 사 등을 병행한 형태학적 분석과 생화학적 동정을 기초로 하고 있다. Multi-locus sequence typing (MLST)는 최근에 사용되 고 있는 분자생물학적 동정은 DNA sequencing을 통해 균주간 의 염기서열 차이를 비교하여 동일 종 내 유전적 변이 특성을 규 명하는 방법이 있다[9]. 이는 정립된 다좌위 효소 전기영동 (multi-locus enzyme electrophoresis, MLEE)을 기반으로 하 지만 DNA sequencing에 의한 다양한 housekeeping gene에

Table 1. Classification of study groups according to the type of clinical specimen

\begin{tabular}{ccc}
\hline Study group & Clinical specimens & No. of samples (\%) \\
\hline 1 & Blood (central line) & $8(20.0)$ \\
2 & Blood (peripheral) & $7(17.5)$ \\
3 & Urine, Sputum & $13(32.5)$ \\
4 & Others & $12(30.0)$ \\
Total & & $40(100)$ \\
\hline
\end{tabular}

Others: pus, wound, CSF(cerebrospinal fluid), body fluid, tissue etc.
서 대립 유전자 부위 약 $500 \mathrm{bp}$ 정도 영역을 사용한다는 점에서 차이가 있다. 또한 housekeeping gene의 서로 다른 염기서열 은 대립 유전자로 인하여 구분되고 균주 typing에 대비하여 식 별할 수 있다는 특징이 있다[10]. 이러한 이유로 약 8 10개 정 도의 housekeeping gene을 사용하여 각 대립유전자 프로 파일 간 차이를 토대로 dendrogram을 만들 수 있다[9, 11]. 본 연구 에서는 국내 소재 3차 병원의 임상검체로부터 분리된 $C$. albicans 40개 균주를 대상으로 MLST 기법을 이용한 유전자형 별 시험을 시행하여 염기서열 변이로 인한 유전학적 특성과 서 로 다른 검체 채취 부위에서 분리된 균주와의 계통학적 연관성 에 대해 알아보고, 인체감염 C. albicans가 감염부위에 따라 나 타나는 유전자의 변이가 감염을 진행하는데 어떠한 역할을 하 는지에 대한 역학적 연구에 기초자료를 제공하고자 하였다.

\section{재료 및 방법}

국내 소재 3 차 병원 진단검사의학과로 검사를 의뢰받은 환자 의 임상검체로부터 C.albicans로 분리 동정 된 임상 분리 균주 40 개를 검체 부위 기준으로 혈액(중심 정맥관)은 그룹1, 혈액(말 초)은 그룹2, 소변 및 객담은 그룹3, 기타부위는 그룹4로 분류하 였다(Table 1). C. albicans의 MLST에 이용될 housekeeping gene을 선정하고 염기서열분석에 필요한 $\mathrm{PCR}$ primer를 제작 하였다(Table 2). C. albicans에 대한 housekeeping gene은 ACC1, VPS13, GLN4, ADP1, RPN2, PMA1, SYA1총 7종류를 사용하였으며, 비교 분석을 위해 C. albicans ATCC 10231 표준 균주를 대조 균주로 사용하였다. 염기서열 분석은 SeqMan 프로 그램(DNASTAR Inc.)을 사용하였으며 최종 분석 전에 판독 오 류를 판별하기 위해 불명확한 염기서열 부분은 수정하는 작업을

Table 2. Specific oligo nucleotide primer sets used for C. albicans MLST

\begin{tabular}{|c|c|c|c|}
\hline & Locus & Sequence $\left(5^{\prime} \rightarrow 3^{\prime}\right)$ & Amplicon size (bp) \\
\hline$A C C 1$ & Acetyl coenzyme A carboxylase & $\begin{array}{l}\text { F GCA AGA GAA ATT TTA ATT CAA TG } \\
\text { R TTC ATC AAC ATC ATC CAA GTG }\end{array}$ & 519 \\
\hline VPS13 & Vacuolar protein sorting protein & $\begin{array}{l}\text { F TCG TTG AGA GAT ATT CGA CTT } \\
\text { R ACG GAT GGA TCT CCA GTC C }\end{array}$ & 741 \\
\hline GLN4 & Glutaminyl tRNA synthase & $\begin{array}{l}\text { F GAG ATA GTC AAG AAT AAA AAA GT } \\
\text { R ATC TCT TTC ATC TTT TGG ACC }\end{array}$ & 483 \\
\hline$A D P 1$ & ATP-dependent permease & $\begin{array}{l}\text { F GAG CCA AGT ATG AAT GAT TTG } \\
\text { R GAG CCA AGT ATG AAT GAT TTG }\end{array}$ & 537 \\
\hline RPN2 & 265 proteasome regulatory subunit & $\begin{array}{l}\text { F TTC ATG CAT GCT GGT ACT TAC } \\
\text { R TTC ATG CAT GCT GGT ACT TAC }\end{array}$ & 447 \\
\hline PMA1 & Plasma membrane $\mathrm{H}^{+}$-ATPase & $\begin{aligned} & \text { F GCC ATT TTC GCT GAT GTT GC } \\
& \text { R CGT GTT GAG TAG ATA CTC TTT GC }\end{aligned}$ & 480 \\
\hline SYA1 & Alanyl RNA synthetase & $\begin{array}{l}\text { F AGA AGA ATT GTT GCT GTT ACT G } \\
\text { R GTT ACC TTT ACC ACC AGC TTT }\end{array}$ & 543 \\
\hline
\end{tabular}


시행하였다.

\section{결 과}

\section{Housekeeping gene의 DNA 염기서열 확인}

$\mathrm{PCR}$ 을 통해 증폭된 7종류의 C. albicans Housekeeping gene인 ACC1, VPS13, GLN4, ADP1, RPN2, PMA1, SYA1는 각각 $519,741,483,537,447,480,543 \mathrm{bp}$ 크기를 나타냈다 (Figure 1).

\section{C. albicans유전자의 MLST 분석}

Mlst.net에 제시된 4개 $A C C 1$, VPS13, $A D P 1, S Y A 1$ 유전자 에 대한 sequence type (ST)결과 총 32종의 allele type을 얻었 으며(Table 3), 이를 토대로 DNA STAR. Meg Align 프로그램을 이용하여 phylogenetic tree를 형성하였다(Figure 2). Phylogenetic tree에서 cut-off 수치 0.1을 기준으로 분석하였을 때, cluster 1에는 urine (8), central line blood (5), sputum (5), peripheral blood (6), others (10)의 총 34개, cluster 2에는 central line blood (4)에서 4개가 위치하였다(Table 4). Cluster 1의 32 균주에 대해 $A C C 1, V P S 13, A D P 1, S Y A 1$ 유전 자와 이에 대한 ST 유형을 사용하여 재분석하였으며, strain 15 , 38은 cluster 1에 속해있는 다른 검체와 연관성이 적어 제외시 켰다(Figure 3). 그 결과 sub-cluster 1과 2로 나누어졌으며, sub-cluster 1에는 central line blood (2), others (5), sputum (4), urine (7)의 총 18 개로 나뉘었으며 sub-cluster 2에는 central line blood(1), others (5), peripheral blood (6), sputum (1), urine (1)의 총 14개로 나뉘었다(Table 5).

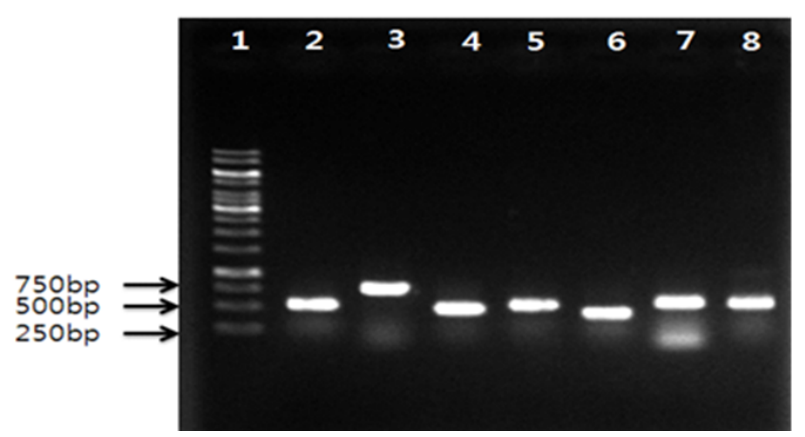

Figure 1. PCR amplification of C. albicans ATCC 10231 Lane1: sizemarker, Lane2: ACC1, Lane3: VPS13, Lane4: GLN4, Lane5: ADP1, Lane6: RPN2, Lane7: PMA1, Lane8: SYA1.

\section{고 찰}

지금까지 미생물의 동정은 미생물을 배양하여 그 형태와 생 화학적 검사 등을 이용하여 시행되고 있지만 표현형 정보의 부 족, 배양의 어려움, 시간적인 단점이 있다[12]. 최근 분자생물학 적인 방법이 발전되어 분자생물학적 동정이 가능하게 되었으 며, DNA hybridization, PCR, RFLP, AFLP, PFGE, DNA

Table 3. Allele type based on four housekeeping genes of $C$. albicans clinical isolates

\begin{tabular}{|c|c|c|c|c|}
\hline \multicolumn{5}{|c|}{ Allele } \\
\hline Strains & $A C C 1$ & VPS13 & $A D P 1$ & SYA1 \\
\hline $\begin{array}{l}\text { Total number } \\
\text { of STs }\end{array}$ & 106 & 280 & 146 & 208 \\
\hline ATCC 10231 & 7 & 4 & 106 & 149 \\
\hline Strain 1 & 3 & 3 & 106 & 25 \\
\hline Strain 2 & 3 & 24 & 106 & 136 \\
\hline Strain 3 & 3 & 45 & 106 & 29 \\
\hline Strain 4 & 7 & 159 & 106 & 136 \\
\hline Strain 5 & 3 & 3 & 128 & 147 \\
\hline Strain 6 & 3 & 159 & 106 & 136 \\
\hline Strain 7 & 77 & 55 & 106 & 29 \\
\hline Strain 8 & 9 & 55 & 106 & 136 \\
\hline Strain 9 & 3 & 58 & 106 & 29 \\
\hline Strain 10 & 3 & 3 & 52 & 29 \\
\hline Strain 11 & 3 & 58 & 30 & 136 \\
\hline Strain 12 & 3 & 279 & 52 & 29 \\
\hline Strain 13 & 3 & 3 & 106 & 178 \\
\hline Strain 14 & 3 & 279 & 14 & 149 \\
\hline Strain 15 & 3 & 58 & 52 & 149 \\
\hline Strain 16 & 9 & 55 & 52 & 149 \\
\hline Strain 17 & 3 & 24 & 106 & 29 \\
\hline Strain 18 & 3 & 3 & 106 & 29 \\
\hline Strain 19 & 7 & 3 & 106 & 136 \\
\hline Strain 20 & 8 & 3 & 106 & 136 \\
\hline Strain 21 & 13 & 3 & 14 & 136 \\
\hline Strain 22 & 3 & 58 & 39 & 192 \\
\hline Strain 23 & 8 & 3 & 128 & 136 \\
\hline Strain 24 & 3 & 4 & 106 & 136 \\
\hline Strain 25 & 3 & 3 & 106 & 29 \\
\hline Strain 26 & 3 & 55 & 128 & 149 \\
\hline Strain 27 & 19 & 58 & 106 & 29 \\
\hline Strain 28 & 3 & 55 & 128 & 149 \\
\hline Strain 29 & 3 & 3 & 106 & 29 \\
\hline Strain 30 & 3 & 20 & 106 & 29 \\
\hline Strain 31 & 7 & 55 & 130 & 149 \\
\hline Strain 32 & 3 & 55 & 128 & 149 \\
\hline Strain 33 & 8 & 3 & 106 & 136 \\
\hline Strain 34 & 3 & 45 & 106 & 29 \\
\hline Strain 35 & 3 & 55 & 146 & 149 \\
\hline Strain 36 & 19 & 58 & 106 & 29 \\
\hline Strain 37 & 13 & 3 & 14 & 136 \\
\hline Strain 38 & 3 & 159 & 52 & 67 \\
\hline Strain 39 & 3 & 3 & 96 & 136 \\
\hline Strain 40 & 3 & 3 & 106 & 29 \\
\hline
\end{tabular}




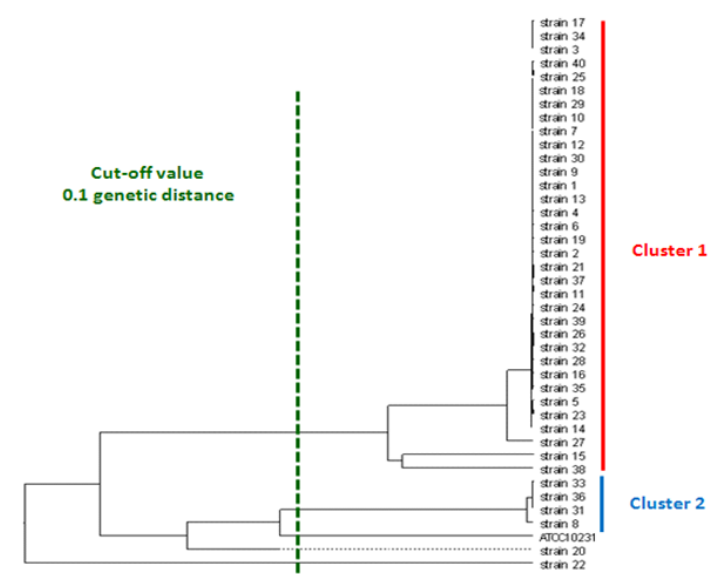

Figure 2. Dendrogram indicating the similarities 40 strains $C$. albicans clinical isolates determined by MLST with 7 housekeeping genes.

Table 4. Classification cluster of clinical isolated C. albicans 38 strains

\begin{tabular}{ccr}
\hline Cluster & Frequency (N) & Specimen (N) \\
\hline 1 & 34 & $\begin{array}{r}\text { urine (8), central line blood (5), sputum } \\
\text { (5), peripheral blood (6), others (10) } \\
\text { central line blood (4) }\end{array}$ \\
\hline
\end{tabular}

Abbreviation: $\mathrm{N}$, number.

sequencing 등이 제시됨에 따라 이들의 유전적 변이를 기반으 로 한 유전자형 분석이 가능해졌다. 그러나 가장 기본적으로 사 용하는 PCR 기법의 경우 종종 돌연변이를 일으키는 미생물 유 전체로 인해 PCR 기능이 감소될 수 있다는 한계점이 있으며, $\mathrm{PFGE}$ 기법은 실험에 걸리는 시간이 4 5일로 길고 노동 집약 적, 데이터 분석이 시험자의 경험으로 다양한 견해를 보인다는 단점이 있다. 최근 이러한 한계점을 보완하고자 제시된 방법인 MLST 분석법은 미생물 유전체가 가지고 있는 4 10개의 housekeeping gene의 염기서열에 근거를 두어 분석하는 것으 로 이를 이용한 역학적 연구는 유전자 변이 추적이 가능하여 전 세계적으로 비교 분석이 가능하다는 장점이 있다[13]. 국내에 서 임상으로부터 분리한 진균에 대해 MLST를 이용한 역학적 연 구는 부족한 실정이며, 최근 중요성이 주목받음에 따라 관련 연 구가 활발히 진행되고 있다[14].

C. albicans는 인체 여러 부위에서 발견되는 정상균무리로 면역력이 약한 사람의 경우 대부분 혈류를 따라 다른 장기에 침 입하여 감염이 빠르게 진행될 수 있다고 보고하였다[15]. 더불 어 광범위한 Fluconazole 사용은 다른 Azole계에 대한 교차내 성을 일으키거나 내성을 유도한다. 이러한 내성 균주에 의한 감 염에 효과적으로 치료할 수 있는 새로운 항진균제 및 분자유전

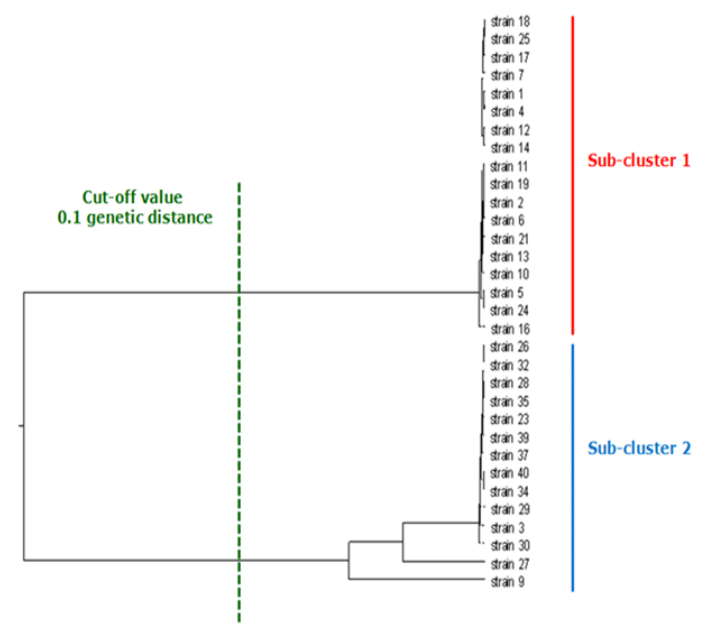

Figure 3. Dendrogram indicating the similarities 32 strains of cluster 1 determined by phylogenetic tree with 4 housekeeping genes.

Table 5. Classification sub-cluster of clinical isolated C. albicans 32 strains

\begin{tabular}{ccc}
\hline Sub Cluster & Frequency $(N)$ & Specimen $(N)$ \\
\hline 1 & 18 & $\begin{array}{c}\text { urine (7), central line blood (2), } \\
\text { sputum (4), Others (5) } \\
\text { urine (1), central line blood (1), } \\
\text { sputum (1) peripheral blood (6), } \\
\text { others (5) }\end{array}$ \\
\hline
\end{tabular}

Abbreviation: $\mathrm{N}$, number.

학적 검사법의 개발로 신속하고 정확한 검출을 할 수 있어야 하 며, 앞으로 항진균제 내성균을 효과적으로 관리하기 위한 연구 가 이루어져야 할 것이다.

Robles 등[16]의 연구에서는 기법간의 비교를 위해 MLST, RAPD, MLEE, Ca3 southern hybridization을 함께 시행하였 으며, C. albicans 총 29 균주를 대상으로 7개 housekeeping gene ACC1, VPS13, GLN4, ADP1, RPN2, PMA1, SYA1를 사 용하였다. 총 $2,834 \mathrm{bp}$ 서열분석에서 61 개의 다형성 부위가 발 견되었고 기존 연구에서 밝혀져 있는 부위 이외에 $A C C 1211$, 317, VPS1353, GLN4169, ADP1229, RPN2158, SYA1202, $219,294,350$ 위치를 새롭게 발견하였다. 유전자별로 다양한 diploid sequence type (DST)이 나왔으며 단독 분리된 균주에 서는 새로운 유형을 보였다. 분리원에 따른 뚜렷한 차이는 없었 으나 sequence type 별로 유사성을 보였다.

본 연구에서는 진균의 전신성 감염에 큰 영향을 미치고 면역 저하 환자의 C. albicans에 의한 감염이 현저하게 증가하고 있 는바, 이에 대한 유전적 특성을 분석하기 위해 국내 소재 3 차 병 원의 임상에서 분리된 C. albicans 40 균주를 대상으로 Robles 
등[16] 연구와 동일한 housekeeping gene을 사용하여 MLST 분석을 수행하였다. Robles 등[16]의 연구에서 도출된 부위 이 외의 다형성 부위는 발견되지 않았으나 본 연구에서는 흔하게 분리되지 않는 $A C C 1$ 의 317, $A D P 1352, R P N 2130,158$ 위치 의 변이가 발견되었으며, mlst.net에 제시된 평균 변이율 보다 더 높은 비율을 보인 부위는 ACC1 281, VPS13281, SYA1 61 임을 확인하였다. 영국 Frank C. Odds는 병원성 Candida속다 섯 균종으로 이에 대한 유전자별 sequencing, SNP 분석, ST, $\mathrm{DST}$ 를 비교하였고 다양한 인종들로부터 분리된 균주들로 AAT1a, ACC1, ADP1, PMIb, SYA1, VPS13, ZWF1a를 이용하 여 MLST를 시행한 결과아시아 지역으로부터 분리된 균주가 분 포된 cluster에 대해 세분화하여 분석한 결과 sub-cluster 1,2 가 동남아시아 지역 균주들과 그 외 아시아 지역 균주들로 나뉜 것을 확인하였다[17]. Chen 등[11] 의 연구에서는 동일 환자에 서 분리된 것을 포함하여 다른 질병 3 가지 군으로부터 분리된 C. albicans 51 균주를 대상으로 PFGE, MLST, ABC typing 등 을 시행하였다. MLST분석에서는 AAT1a (10), ACC1 (6), $A D P 1(10), M P I b$ (15), SYA1 (13), VPS13(16), ZWF1b (13)의 총 83 개 다형성 부위를 관찰하였으며, 같은 환자에서 분리된 균 주끼리 상관성이 있어 질병에 따른 균주 간 동일성을 보였다고 보고하였다[11]. 위의 연구들에 따르면 동일 환자 내에서의 균 주, 분리원에 따른 연관성을 보고하였다. 본 연구 대상의 균주들 은 기존에 연구되었던 분류와 큰 특성 차이는 보이지 않았지만 혈류감염을 일으키는 C. albicans 균주들이 동일한 cluster안 에 있는 것을 확인할 수 있었다. Phylogenetic tree에서 cut-off 수치 0.1 을 기준으로 분석하였을 때 cluster 1에는 urine (8), central line blood (5), sputum (5), peripheral blood (6), others (10)의 34개, cluster 2에는 central line blood (4)의 4 개가 위치하였다. Cluster 1의 32 균주에 대해 $A C C 1, V P S 13$, $A D P 1, S Y A 1$ 유전자와 이에 대한 ST 유형을 사용하여 재분석한 결과 sub-cluster 1과 2로 나누어졌으며, sub-cluster 1에는 central line blood (2), others (5), sputum (4), urine (7)의 총 18 개, sub-cluster 2에는 central line blood (1), others (5), peripheral blood (6), sputum (1), urine (1)의 총 14개로 나뉘 었다.

본 연구 결과 검체간의 뚜렷한 분류는 나타나지 않았으나 urine과 sputum, peripheral blood, central line blood 균주 의 크게 세 분류로 나뉘었다. 기타 검체의 경우 정확한 채취 부위 의 임상정보를 알수 없어 데이터 분석에 큰 의미는 부여할 수 없 었지만 다양한 위치에 있는 것으로 보아 전신 감염의 가능성이 큰 것으로 생각되며, urine과 sputum에서 분리된 균주들은 감
염과 직접적인 관계는 아닌것으로 여겨진다. 또한 peripheral blood, central line blood에서 분리된 균주는 채취 부위에 따 른 감염성 원인 균주임과 동시에 정상균무리에 의해 혈류 감염 으로 이어진 것인지에 대한 가능성을 추정할 수 있었다. 검체 채 취 부위별로 약간의 연관성을 발견할 수 있었으며 나이, 성별에 따른 관련성은 없는 것으로 확인되었다. 유전자별 특정 단독 부 위 변이에 대한 정확한 원인 규명은 어려우나 균주 내 같은 부위 의 변이를 갖는 집단이 계통학적으로 유사성을 보일 수 있다는 보고와 일치하는 결과를 나타냈다[18]. MLST를 이용한 유전자 분석은 사용되는 유전자 수가 많아서 비용이 많이 드는 한계가 있지만 환자 검체 분리원에 따라 유전적으로 다양한 균종들의 변이를 확인하는 데는 유용할 것으로 생각되며, 항균제 내성과 관련된 유전자의 변이 양상 및 계통학적 상관관계를 추정할 수 있을 것으로 사료된다. 이와 같이 환자의 질병과 생체내의 환경 에 따라 연관된 C. albicans 유전자들의 변이 양상에 대한 자료 들의 지속적인 축적으로 새로운 유전자 표적의 항균제 개발 및 감염병의 작용기전을 연구하기 위한 역학적 감시체계 구축에 도움이 될 것으로 사료된다.

\section{요 약}

본 연구에서는 국내 대전 소재 3차 병원 임상에서 분리된 Candida albicans 40 균주를 대상으로 균주 분리원에 따라 7종 류의 housekeeping gene에 대한 염기서열 변이를 확인하고 MLST 분석을 통해 균주간의 계통학적 연관성에 대한 연구를수 행하여 다음과 같은 결과를 얻었다. Phylogenetic tree 분석 결 과 sub-cluster 1 로 central line blood (2), others (5), sputum (4), urine (7)을 포함해 총 18 개가 분류되었으며, sub-cluster 2로는 central line blood (1), others (5), peripheral blood (6), sputum (1), urine (1)을 포함해 총 14개가 분류되어 동일 채취 부위에서 분리된 균주는 유전학적으로 유사성을 가지고 있을 가능성이 있음을 확인하였다. 앞으로 분리지역과 상병 등 에 따른 C. albicans 유전자들의 변이 추세에 대한 자료의 축적 과 임상 검체에 따른 계통학적 관계를 추정하여 감염병 연구 및 역학적 감시체계 구축에 도움이 될 것으로 생각된다.

Acknowledgements: This research was supported by a fund (2016-ER4702-00) by Research of Korea Centers for Disease Control and Prevention.

Conflict of interest: None 


\section{REFERENCES}

1. Kim TH, Lee YS, Lee MK, Lee KM. Species distribution and susceptibilities to azoles of Candida species including C. tropicalis in a Tertiary Burn Center. Korean J Clin Microbiol. 2010;13: 79-84.

2. Fridkin SK. The changing face of fungal infections in health caresettings. Clin Infect Dis. 2005;41:1455-1460.

3. Chang MS, Woo JH. Opportunistic fungal infection. Hanyang Med Rev. 2006;26:25-33.

4. Toscano CM, Jarvis WR. Emerging issues in nosocomial fungal infections. Curr Infect Dis Rep. 1999;1:347-361.

5. Marcio Nucci, Kieren A. Marr. Emerging fungal diseases. Clin Infect Dis. 2005;41:521-526.

6. Ahn GY, Jang SJ, Lee SH, Jeong OY, Chaulagain BP, Moon DS, et al. Trends of the species and antimicrobial susceptibility of microorganisms isolated from blood cultures of patients. Korean J Clin Microbiol. 2006;9:42-50.

7. Kim US, Jung SI. Invasive fungal infections in the era of antifungal resistance. Korean J Med. 2015;88:518-524.

8. Farzad Katiraee, Vahid Khalaj, Ali Reza Khosravi, Mahboubeh Hajiabdolbaghi. Sequences type analysis of Candida albicansisolates from Iranian human immunodeficiency virus infected patients with oral candidiasis. Acta Medica Iranica. 2014;52: 187-191.

9. Bougnoux ME, Morand S, d'Enfert C. Usefulness of multilocus sequence typing for characterization of clinical isolates of Candida albicans. J Clin Microbiol. 2002;40:1290-1297.

10. Bougnoux ME, Tavanti A, Bouchier C, Gow NA, Magnier A,
Davidson $\mathrm{AD}$, et al. Collaborative consensus for optimized multilocus sequence typing of Candida albicans. J Clin Microbiol. 2003;41:5265-5266.

11. Chen KW, Chen YC, Lo HJ, Frank C. Odds, Wang TH, Lin CY, et al. Multilocus sequence typing for analyses of clonality of Candida albicans strains in Taiwan. J Clin Microbiol. 2006;44: 2172-2178.

12. Jang SJ. Molecular diagnostics for detection of microorganism. J Clin Microbiol. 2003;6:1-6.

13. Byun JH, Yoo JH, Park Chulmin, Lee Dg, Park SH, Choi SM. Molecular epidemiologic analysis of community-onset extended spectrum beta-lactamase (ESBL) producing Escherichia coli using infrequent-restric-tion-site polymerase chain reaction (IRS_PCR) with comparison by pulsed-field gel electrophoresis (PFGE). Infect Chemother. 2012;44:5-10.

14. Kim YS, Jang SJ. Basic concepts of bacterial taxonomy. Korean J Clin Microbiol. 2012;15:79-87.

15. Jeong SK, Kim SY, Bong JM, Paik EK, Lee KH, Lee SO, et al. A case of psoas abscess due to Candida albicans. Infection and Chemotherapy. 2003;35:325-328.

16. Juan C. Robles, Larry Koreen, Steven Park, David S. Perlin. Multilocus sequence typing is a reliable alternative method to DNA fingerprinting for discriminating among strains of Candida albicans. J Clin Microbiol. 2004;42:2480-2488.

17. Frank C. Odds, Mette D. Jacobsen. Multilocus sequence typing of pathogenic Candida species. Eukaryotic Cell. 2008;7: 1075-1084.

18. Kim JI, Lim JH, Lee JW, Lee HB. Phylogenetic relationship of Microcystis (Cyanolhyceae) based on partial 16S rRNA gene sequences in Korea. Algae. 2002;17:153-159. 